\title{
Drought Tolerance Enhancement with Co-Overexpression of DREB2A and APX in Indica Rice (Oryza sativa L.)
}

\author{
Jagtap Sandhya, Talakayala Ashwini, Ravula Manisha, Mahankali Vinodha, Ankanagari Srinivas*
}

Department of Genetics \& Biotechnology, Osmania University, Hyderabad, India

Email: *srinivasmessage@gmail.com

How to cite this paper: Sandhya, J., Ashwini, T., Manisha, R., Vinodha, M. and Srinivas, A. (2021) Drought Tolerance Enhancement with Co-Overexpression of DREB2A and APX in Indica Rice (Oryza sativa L.). American Journal of Plant Sciences, $12,234-258$.

https://doi.org/10.4236/ajps.2021.122014

Received: January 10, 2021

Accepted: February 23, 2021

Published: February 26, 2021

Copyright $\odot 2021$ by author(s) and Scientific Research Publishing Inc. This work is licensed under the Creative Commons Attribution International License (CC BY 4.0).

http://creativecommons.org/licenses/by/4.0/

(c) $\underset{\mathrm{By}}{\mathrm{i}}$ Open Access

\begin{abstract}
Rice is a major cereal crop providing food and energy to more than half of world's population and drought is a challenging abiotic stress limiting rice production. Engineering drought tolerance trait is a major bottle neck because of multigenic control and complex nature. Two promising candidate genes utilized in engineering drought tolerance include DREB2A transcription factor (a master regulator of downstream stress inducible genes) and APX (an important ROS scavenging enzyme). Overexpression of DREB genes has shown encouraging results but with a negative impact on plant morphology and production. Moreover, co-expression of DREB2A and APX genes' influence on drought stress has not been studied. Hence, in the present study, overexpression of single genes DREB2A or APX and co-expression of these genes were studied for enhancement of drought tolerance in indica rice. Both genes under control of CaMV 35S promoter were transferred by Agrobacterium transformation into rice variety BPT5204 popular for slender grains in South India. Confirmation of T-DNA integration into rice genome was done with PCR analysis of transgenes. Homozygous transgenic lines of DREB2A, APX and DREB2A-APX generated in $\mathrm{T}_{3}$ generation were evaluated for drought tolerance during seed germination, vegetative and reproductive stages. In seed germination stage, transgenic lines exhibited higher germination rates on $200 \mathrm{mM}$ mannitol MS medium in comparison to WT. In vegetative stage, with-holding water for 7 days transgenic lines exhibited higher chlorophyll, proline, reducing sugars and enhanced activities of APX, SOD and catalase enzymes as well as reduced MDA content. The qRT-PCR analysis revealed higher relative transgene expression under drought stress. In reproductive stage, before maturity with-holding water for 7 days and restoring normal conditions, transgenic lines developed longer panicles and a higher number of grains/plant compared to WT. The overall results indicate that co-expression
\end{abstract}


of DREB2A and APX can provide enhanced drought tolerance in rice plants to combat climate change conditions.

\section{Keywords}

APX, DREB2A, Reactive Oxygen Species, Transgenic Rice, Drought

Tolerance

\section{Introduction}

Different abiotic environmental stresses have been responsible for limiting the conditions for plant exploitation and productivity worldwide. Various stresses like salinity, radiation and temperature fluctuations have a great impact on survival, biomass and yield potential of different food crops [1]. Improvement of yield and maintaining the yield stability of food crops under both normal and stress conditions becomes the most important factor for the food security of the ever increasing population [2]. Drought stress is one of the most adverse factors and considered as a severe threat to growth and productivity of sustainable crops [3]. The effects of drought are thought to be more severe with increasing water deficit conditions and climate changes [4].

Plants during drought stress undergo three major interactive alterations leading to changes in expression of genes [5], biosynthesis of metabolites [6] [7] and production of proteins [8] that confer tolerance to stress leading to life sustenance. At first, in response to drought stress, plants induce the expression of different functional and regulatory genes [9]. Key genes identified in various pathways expressed under drought stress include different transcription factors: viz., DRE-binding protein (DREB)/C-repeat-binding factor (CBF), ABA-binding factor (ABF), MYC, MYB [10] [11], ABA-responsive element (ABRE) and dehydration responsive element [12]. Second, plants respond to drought stress by enhancing the production of primary and secondary metabolites that act as osmolytes, stress signals, antioxidants and osmoprotectants. The increased accumulation of these osmolytes maintains the turgor pressure by allowing the water to enter the cells by lowering the osmotic potential. Third, plants scavenge the reactive oxygen species (ROS) with antioxidative defense system to protect the cells from oxidative injury under drought stress conditions. Various ROS free radicals such as hydroxyl radical, hydrogen peroxide, superoxide and singlet oxygen are produced and accumulation of ROS during drought stress enhances lipid peroxidation and protein oxidation resulting in severe damage to plant cells [13] [14].

The ROS produced under normal conditions are maintained in balance by the action of different antioxidants in the cell. Many enzymatic and non-enzymatic antioxidant systems are involved in scavenging and reducing the ROS levels and maintain the cellular redox balance. Enzymatic system consists of ascorbate peroxidase (APX), superoxide dismutase (SOD), glutathione peroxidase (GPX) and 
catalase (CAT). In plants, APX is the frontline key enzyme of hydrogen peroxidase-detoxification system (ascorbate-glutathione cycle), in which ascorbic acid is utilized as electron donor in reducing $\mathrm{H}_{2} \mathrm{O}_{2}$ to water [15]. APX plays a vital role in scavenging the ROS and under stress conditions APX activities enhances in cytosolic, chloroplastic and peroxisomal compartments in all the plant species. APX is regulated at transcriptional level and more strongly at post-transcriptional level, for instance, the cytosolic APX activity is increased in pea during drought [16] and in the alx 8 (altered expression of APX2) mutants of Arabidopsis improved drought tolerance is revealed [17] [18].

In plants, as a result of drought stress, ROS species generated are highly toxic and need to be detoxified rapidly. Transgenic improvements of plants through detoxification strategy have been achieved for abiotic stress tolerance which include overexpressing enzymes glutathione peroxidase, glutathione reductases [19], superoxide dismutase [20], and ascorbate peroxidases [21] [22] involved in oxidative protection. The peroxisomal or cytosolic APX from poplar over expression increases plant performance under drought in transgenic tobacco [21] [22]. Moreover, possibility of enhancing tolerance towards drought stress transformation of plants with stress inducible genes viz. regulatory proteins such as DREB transcription factors has emerged. In major cases, constitutive DREB overexpression not only led to activate stress responsive genes and accumulation of low molecular protectants, but affect plant morphology and production [23]. Through the transcription factors, many genes can be regulated simultaneously in stress responses [24]. The transgenic approach of the introduced TF gene allows controlling the timing, expression levels and tissue specificity for its optimal function. If the action of a given gene or transcription factor is desired in specific organ at specific time or under specific stress conditions, it is important to better integrate gene action and physiology. Hence, in this study co-expression of DREB2A and APX genes was carried out in indica rice to develop drought tolerance in BPT5204 (Samba Masuri) variety which is sensitive to abiotic stresses.

\section{Materials and Methods}

\subsection{Vectors Construction}

The DREB2A, APX, and DREB2A-APX clones were maintained in HB101 cells. The DREB2A and APX cassettes were cloned at Hind III and Pst I sites independently into pCAMBIA1300. In addition, the DREB2A and APX cassettes were ligated and cloned at Hind III and Pst I sites of pCAMBIA1300 and mobilized into Agrobacterium tumefaciens (LBA4404) by freeze thaw method,

\subsection{Agrobacterium Mediated Genetic Transformation in Rice}

Agrobacterium strains harbouring DREB2A, APX and DREB2A-APX cassettes were employed for genetic transformation experiments in rice. Embryogenic calli derived from the scutellum of BPT 5204 indica rice cultivar were utilized for genetic transformation. Calli were infected with Agrobacterium cultures har- 
bouring DREB2A, APX and DREB2A-APX cassettes independently. Infected calli were subjected to two rounds of selection on medium supplemented with 40 and $50 \mathrm{mg} / \mathrm{l}$ hygromycin. Putatively transformed calli were cultured on proliferation medium for one week and then transferred onto regeneration medium [25] Regenerated shoots were later transferred to rooting medium and rooted plantlets were established in pots and grown to maturity in net house.

\subsection{Molecular Analysis}

Genomic DNA from the putatively transformed DREB2A, APX and DREB2A-APX plants along with WT control plants was isolated according to the protocol described in Sigma-Aldrich genomic DNA extraction kit. PCR analyses were performed using DREB2A gene specific forward

5'-CCTCATTGGGTCAGGAAGAA-3' and reverse

5'-AACCCATCATCTCCCTCTTG-3' primers for DREB2A and DREB2A-APX putative transformants. Further, APX gene specific forward

5'-ATCAGCTTGCTGGAGTGGTT-3' and reverse

5'-GCCGTTGAACCATCTGATTT-3' primers were employed for the PCR analyses of APX and DREB2A-APX primary transformants. Plasmid DNAs were used as positive controls and DNA from WT control plants was used as a negative control. The amplified PCR products were analysed on $1 \%$ agarose gel.

Southern blot analysis was carried out for DREB2A, APX and DREB2A-APX transgenic plants using $15 \mu \mathrm{g}$.genomic DNA digested with SacI restriction enzyme. The digest was resolved on $1 \%$ agarose gel and the bands were transferred onto nylon membrane. The membrane was then exposed to UV in UV cross-linker [26] and probed with $h p h$ coding regions after radiolabelling with $\alpha^{-32} \mathrm{P}$ radiolabelled dCTP, in corresponding lines. Following the hybridization, the membrane was washed according to the manufacturer's instructions.

\subsection{Identification of Homozygous Lines}

Homozygous DREB2A, APX and DREB2A-APX lines were generated by germinating the $T_{1}$ seeds of transgenic plants on MS medium supplemented with 40 $\mathrm{mg} / \mathrm{l}$ hygromycin. After 7 days, the germinated seedlings were transferred to pots and grown to maturity. The $\mathrm{T}_{2}$ seeds obtained were germinated on MS medium supplemented with $40 \mathrm{mg} / \mathrm{l}$ hygromycin to identify the homozygous lines.

\subsection{Drought Stress Treatment at Germination and Seedling Stage}

To assess the drought tolerance of transgenic lines, the seeds were first surface sterilized with ethanol and mercuric chloride followed by washing with sterile distilled water for 5 times and the seeds were germinated on MS medium containing $200 \mathrm{mM}$ Mannitol. After 7 days, the germination rates of different transgenic lines were recorded. Seed germination rate (\%) was assessed using the following formula:

$$
\text { Seed germination rate }(\%)=\frac{\text { Number of seeds germinated }}{\text { Total number of seeds tested }} \times 100
$$


To assess the drought tolerance at seedling stage, seeds of DREB2A, APX, DREB2A-APX and WT were grown in vermiculate for one week. These seedlings were transferred to Hoagland's solution supplemented with $200 \mathrm{mM}$ mannitol. After 7 days of treatment, the seedlings were transferred to fresh Hoagland solution for recovery. Data was recorded on survival rate, root length, shoot length and biomass of the seedlings after treatments.

\subsection{Drought Stress Treatment at Vegetative Stage}

To analyse the drought stress tolerance ability at vegetative stage, the transgenic plants along with WT control plants 65 days old were subjected to drought stress by withholding water for 7 days. Data regarding chlorophyll content, reducing sugars, proline content, MDA, APX activity, SOD, catalase, photosynthetic rate and relative water content were estimated from the leaves of 65 day old plants.

\subsection{Estimation of Chlorophyll Content}

Approximately $25 \mathrm{mg}$ of leaf tissue was collected from transgenic lines and WT control plants and immersed in $80 \%$ acetone and incubated in dark for 2 days. The extracted chlorophyll from the leaf tissues were measured in spectrophotometer at 663 and $647 \mathrm{~nm}$ for chl a and chl b, respectively. Total chlorophyll content was estimated according to the procedure described by Lichtenthaler, et al., (1983) [27].

\subsection{Estimation of Reducing Sugars}

The leaf samples (100 mg) collected from transgenic and WT control plants were ground to fine powder in liquid nitrogen. Ethanol (80\%) was used in extraction of reducing sugars at $95^{\circ} \mathrm{C}$. The extraction was concentrated by incubating the solution at $80^{\circ} \mathrm{C}$ for 2 hours. Finally, the concentrate was dissolved in distilled water $(10 \mathrm{ml})$ and reducing sugars were estimated according to Miller (1959) [28].

\subsection{Estimation of Proline Content}

Proline was estimated according to Edit Abraham, et al., (2010) [29]. Leaf material $(1 \mathrm{~g})$ of transgenic and WT control plants were ground in $20 \mathrm{ml}$ of $3 \%$ sulfosalicyclic acid and centrifuged. To $2 \mathrm{ml}$ of supernatant, glacial acetic acid (2 $\mathrm{ml})$ and ninhydrin $(2 \mathrm{ml})$ were added and boiled at $100^{\circ} \mathrm{C}$ for one hour. Later, the tubes were cooled to room temperature, added with toluene $(4 \mathrm{ml})$ and vigorously mixed. The chromophore (toluene) was separated from the aqueous phase and its absorbance was measured at $520 \mathrm{~nm}$.

\subsection{Estimation of MDA}

The leaf tissue of transgenic and WT control plants were homogenized in $5 \mathrm{ml}$ of trichloroacetic acid $(0.1 \%)$ and centrifuged. To $500 \mu \mathrm{l}$ of supernatant, $20 \%$ TCA $\left(4 \mathrm{ml}\right.$ ) containing $0.5 \%$ thiobarbituric acid was added and incubated at $95^{\circ} \mathrm{C}$ for 
$30 \mathrm{~min}$. Later the tubes were quickly cooled on ice and centrifuged. Absorbance of the supernatant was read at $532 \mathrm{~nm}$ to estimate the MDA content according to Hagege, et al., (1995) [30].

\subsection{Estimation of APX Activity}

APX activity was measured according to the protocol described by Nakano and Kozi, (1987) [31]. The leaf tissue (0.5 g) of transgenic and WT control plants were powdered in liquid nitrogen and $2.5 \mathrm{ml}$ of $50 \mathrm{mM}$ potassium phosphate buffer containing $0.04 \mathrm{M} \mathrm{KCl}, 1 \mathrm{mM}$ reduced ascorbate (ASC), $1 \mathrm{mM}$ PMSF and 8\% PVPP: ( $\mathrm{pH}$ 6.0) were added and centrifuged. The supernatant was used for estimating different enzyme activities.

To $25 \mu \mathrm{l}$ of supernatant, $1 \mathrm{ml}$ of reaction buffer containing $50 \mathrm{mM}$ potassium phosphate buffer, ( $\mathrm{pH} 7.0$ ) and $10 \mathrm{mM}$ ascorbic acid were added and mixed gently. Non-specific degradation of ascorbate was determined by taking the absorbance at $290 \mathrm{~nm}$ for $3 \mathrm{~min}$ at $25^{\circ} \mathrm{C}$. Later, $200 \mathrm{mM} \mathrm{H} \mathrm{H}_{2}$ was added to the mixture and absorbance was noted at $290 \mathrm{~nm}$ for $3 \mathrm{~min}$ at $25^{\circ} \mathrm{C}$ to measure the decrease in the reaction rate. Specific activity of APX was estimated from the extinction coefficient of $2.8 \mathrm{mM}^{-1} \cdot \mathrm{cm}^{-1}$ [32].

\subsection{Estimation of SOD}

SOD was determined according to Giannopolitis and Ries (1977) [33]. To $100 \mu \mathrm{l}$ of supernatant, $3 \mathrm{ml}$ of reaction mixture containing $50 \mathrm{mM}$ potassium phosphate buffer ( $\mathrm{pH}$ 7.8), $0.1 \mathrm{mM}$ EDTA, $13 \mathrm{mM}$ methionine, $75 \mu \mathrm{M}$ NBT and 2 $\mu \mathrm{M}$ riboflavin were added and exposed to 5000 lux light for $15 \mathrm{~min}$. SOD activity was estimated by measuring the inhibition of photochemical reduction of nitroblue tetrazolium (NBT). The amount of enzyme required to inhibit $50 \%$ reduction of NBT is termed as one unit SOD.

\subsection{Estimation of Catalase}

Catalase activity was measured in the leaf tissue of transgenic plants as per the protocol described by Aebi (1984) [34]. The leaf material of transgenic and WT control plants were homogenized in $50 \mathrm{mM}$ phosphate buffer ( $\mathrm{pH}$ 7.0) and centrifuged. The supernatant was mixed with hydrogen peroxide-phosphate buffer ( $\mathrm{pH} 7.0)$ and the time was recorded for decreasing the OD value from 0.45 to 0.4 at $240 \mathrm{~nm}$ in a spectrophotometer.

\subsection{Measurement of Photosynthetic Rates and Water-Use-Efficiency}

Young leaves of transgenic and WT control plants were selected to measure the photosynthetic rates and WUE in an automated portable infrared $\mathrm{CO}_{2} / \mathrm{H}_{2} \mathrm{O}$ gas analyser. The young leaf was enclosed in a micro-chamber for two minutes, later the data on photosynthetic rates and WUE were calculated under normal and drought stress conditions. 


\subsection{Relative Water Content}

The RWC was determined according to Gozale and Gonzalez-villar (2001) [35]. The initial fresh weight of transgenic and WT control plant leaves were noted and the leaves were allowed to dry at room temperature until no further loss of weight is observed (desiccated weight). After that, the leaves are further dried by incubating at $70^{\circ} \mathrm{C}$ for 24 hours and dry weight was noted. The RWC was calculated using the formula:

RWC $(\%)=($ desiccation weight - dry weight $) /($ fresh weight - dry weight $) \times 100$

\subsection{Drought Stress Treatment at Reproductive Stage}

To test the drought stress tolerance at reproductive stage, transgenic lines along with WT control plants ( 85 - 95 days old) were subjected to drought stress by withholding water for 7 days. After drought treatment, the plants were allowed to grow under normal conditions till maturity and the data on panicle length and grain yield were recorded.

\subsection{Quantitative Real Time PCR (qRT-PCR)}

For qRT-PCR analysis, total RNA was extracted from the transgenic plants along with WT control plants subjected to drought stress for 7 days. First strand cDNA was synthesized from the RNA extracted and employed for qRT-PCR analyses using SYBR green master mix with Applied Biosystems 7500 real time PCR system programmed with $94^{\circ} \mathrm{C}(45 \mathrm{sec}), 59^{\circ} \mathrm{C}(30 \mathrm{sec})$ and $72^{\circ} \mathrm{C}(45 \mathrm{sec})$ for 35 cycles. All the reactions were carried in triplicates and the relative expression levels were calculated using $2^{-\Delta \Delta c t}$ method employing actin gene as a reference. The primers employed in $\mathrm{qRT}-\mathrm{PCR}$ are listed in Table 1.

\subsection{Statistical Analysis}

All the experiments were carried in triplicates with 6 plants per batch. All the data recorded were tested for statistical significance using Student's $t$-test. ${ }^{* *} \mathrm{P}<$ 0.01 and ${ }^{\star} \mathrm{P}<0.05$ represent significant differences at $1 \%$ and $5 \%$ level of significance, respectively compared with the WT control.

Table 1. Primers used in qRT-PCR for quantifying relative expression levels of DREB2A and APX genes in normal and drought stress exposed plants of WT and DREB2A, APX and DREB2A-APX transgenic lines.

\begin{tabular}{ccc}
\hline S. No. & Primer Name & Primers Sequence \\
\hline 1 & ACTIN-F & 5'-GAGTATGATGAGTCGGGTCCAG-3' \\
2 & ACTIN-R & 5'-ACACCAACAATCTCAAACAGAG-3' \\
3 & APX-F & 5'-CTTCCTGATGCGAAGAAAGG-3' \\
4 & APX-R & 5'-TTCGCGTAATGATCCACAAA-3' \\
5 & DREB2A-F & 5'-CCGGCCACTATACCTTCTGA-3' \\
6 & DREB2A-R & 5'-AGTCTTCCGCTCCTGACAAA-3' \\
\hline
\end{tabular}




\section{Results}

\subsection{Generation of Transgenic Lines}

The DREB2A, APX and DREB2A-APX cassettes (Figures 1(A)-(C)) in pCAMBIA1300 vectors were mobilized into Agrobacterium (LBA4404) by freeze thaw method, independently. Embryogenic calli of BPT 5204 indica rice cultivar induced on callus induction medium were infected by Agrobacterium strains harbouring DREB2A, APX and DREB2A-APX cassettes in different batches. The putative transformed calli of BPT 5204 were selected on hygromycin medium and regenerated (Figure 2(A) \& Figure 2(B)). A total of 11, 9 and 13 transformants were

(A)

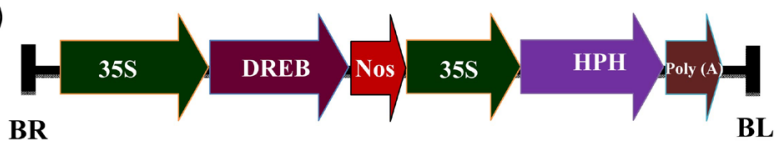

(B)

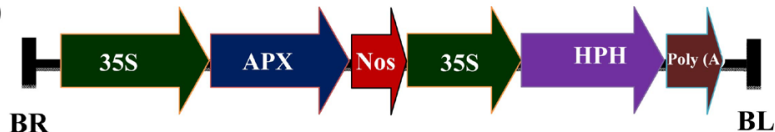

(C)

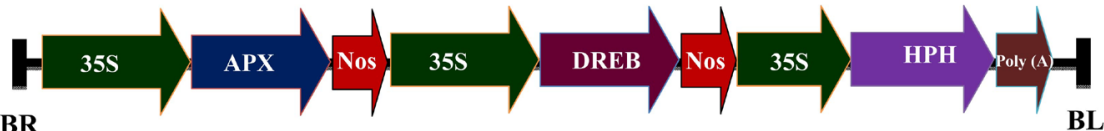

Figure 1. T-DNA region showing expression cassettes of (A) DREB2A, (B) APX and (C) DREB2A-APX driven by CaMV 35S promoter in pCAMBIA1300 vector used for Agrobacterium mediated transformation in the rice variety BPT5204 (Samba Mahsuri).

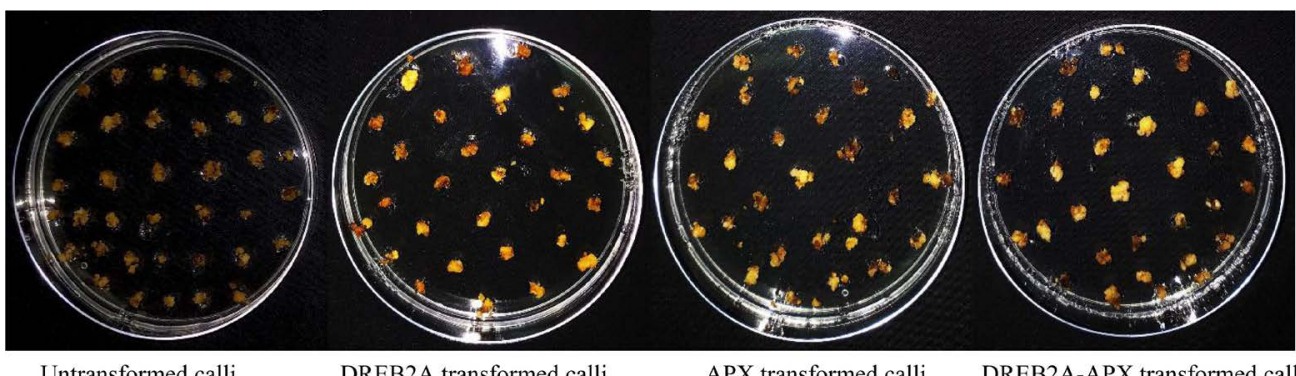

(A)

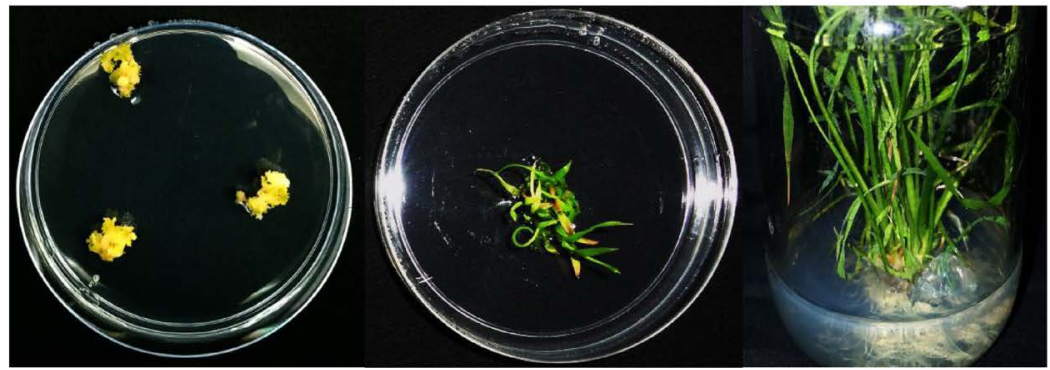

(B)

Figure 2. Selection and regeneration of transformants. (A) Selection of DREB2A, APX and DREB2A -APX transformed calli on MS medium supplemented with $50 \mathrm{mg} / \mathrm{l}$ hygromycin. (B) Regeneration of shoots and roots from hygromycin resistant calli. 
developed from 2684, 2154 and 2986 calli. All the regenerated plantlets were hardened and maintained in nethouse till maturity.

\subsection{PCR and Southern Blot Analysis}

PCR analysis showed an amplification band of $404 \mathrm{bp}$ with APX gene specific forward 5'-ATCAGCTTGCTGGAGTGGTT-3' and reverse 5'-GCCGTTGAACCATCTGATTT-3' primers corresponding to APX region in APX and DREB2A-APX transformants (Figure 3(A)). Similarly, PCR analysis of DREB2A and DREB2A-APX transformants exhibited 773 bp amplicon corresponding to DREB2A region with DREB2A gene specific forward 5'-CCTCATTGGGTCAGGAAGAA-3' and reverse 5'-AACCCATCATCTCCCTCTTG-3' primers (Figure 3(B)). Further, Southern blot analysis of genomic DNA of DREB2A, APX and DREB2A-APX transformants, digested with Sac I restriction enzyme and probed with $h p h$ coding sequence revealed $1.5 \mathrm{~kb}$ hybridisable band, whereas WT control failed to show such band with the same probe (Figure 4).

\subsection{Seed Germination Rates and Seedling Growth}

To assess the drought tolerance of transgenic lines at germination stage, DREB2A,

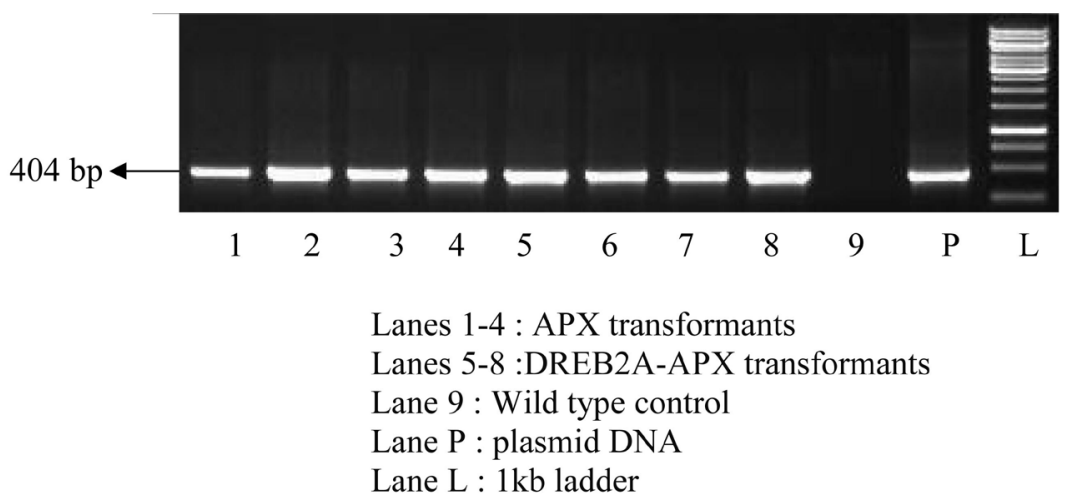

(A)

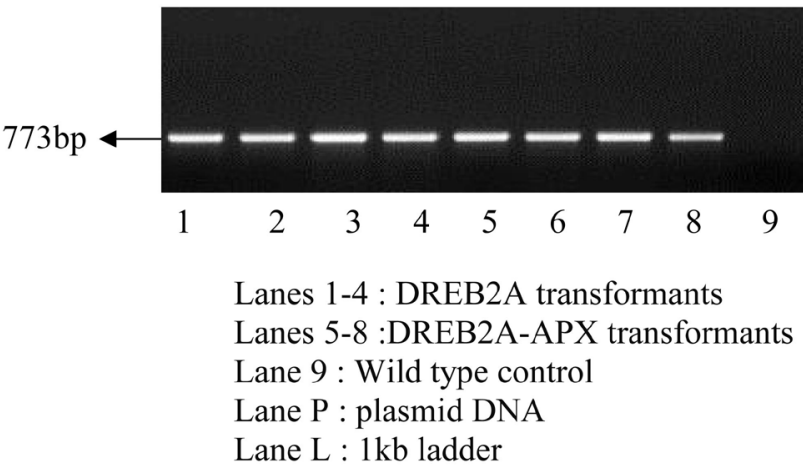

(B)

Figure 3. PCR analysis of WT and transgenic lines. (A) PCR analysis of APX and DREB2A-APX putative transformants for the presence of APX region, (B) PCR analysis of DREB2A and DREB2A-APX putative transformants for the presence of DREB region. 


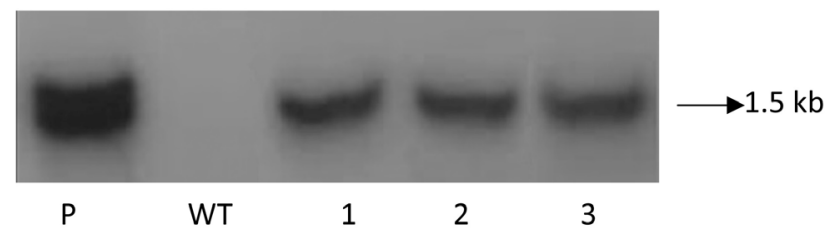

Lane P : Positive control

Lane WT : Wild type control plant

Lane 1 : APX transformant

Lane 2 : DREB2A transformant

Lane 3 : DREB2A-APX transformant

Figure 4. Southern blot analysis of $h p h$ gene in DREB2A, APX, and DREB2A-APX putative transformants.

APX and DREB2A-APX transgenic lines seeds along with WT seeds were germinated on MS media supplemented with $200 \mathrm{mM}$ mannitol. After 7 days of drought stress treatment, DREB2A, APX and DREB2A-APX transgenic line exhibited higher $(73.15 \pm 6.28,75.97 \pm 4.98$ and $84.62 \pm 5.12)$ germination rates in comparison to WT control $(23.59 \pm 2.87)$ plants (Figure $5(\mathrm{~A})$ and Table 2).

Seedlings of DREB2A, APX and DREB2A-APX transgenic lines subjected to drought stresses disclosed higher survival rate, biomass, shoot and root length in DREB2A, APX and DREB2A-APX compared to WT plants. Under drought stress conditions, DREB2A, APX and DREB2A-APX transgenic lines exhibited higher $75.16 \% \pm 5.24 \%, 81.92 \% \pm 3.59 \%$ and $89.68 \% \pm 7.25 \%$ survival rates compared to WT $(30.15 \% \pm 3.24 \%)$ plants. Different transgenic and WT plants exhibited $100 \%$ survival rate under normal conditions (Figure 5(B) and Table 3). The biomass produced by the transgenic DREB2A, APX and DREB2A-APX plants $(109.96 \pm 6.37,115.37 \pm 1.54$ and $135.81 \pm 4.91 \mathrm{mg} \mathrm{FW})$ were significantly higher than that of WT $(62.54 \pm 6.83 \mathrm{mg} \mathrm{FW})$ plants at drought stress. In addition, significantly higher shoot lengths were recorded by DREB2A, APX and DREB2A-APX under drought stress $(7.91 \pm 0.24,8.11 \pm 0.15$ and $8.46 \pm 0.32 \mathrm{~cm})$ compared to WT $(3.02 \pm 0.42)$ plants, respectively, under similar stress conditions. Moreover, higher root lengths of $7.15 \pm 0.54,6.02 \pm 0.18$ and $7.34 \pm 0.49$ under drought stress were exhibited by DREB2A, APX and DREB2A-APX transgenic lines while WT plants showed $2.85 \pm 0.41$ under similar stress conditions (Figure 5(B) and Table 3).

\subsection{Effect of Drought Stress on Vegetative Growth}

The transgenic lines DREB2A, APX and DREB2A-APX along with WT control plants were subjected to drought stress by withholding water for 7 days. After stress treatment, the plants were allowed to grow under normal conditions till maturity. The transgenic lines were able to resume growth, whereas WT control plants are retarded in growth (Figure 6).

\subsection{Chlorophyll, Reducing Sugars and Proline Content}

Transgenic lines DREB2A, APX and DREB2A-APX exhibited significantly higher 


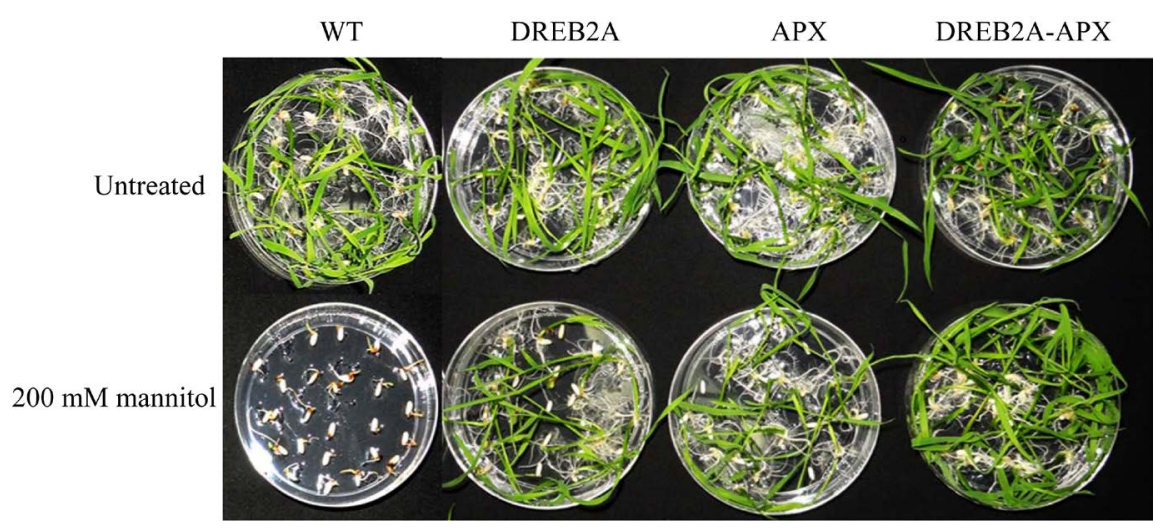

(A)

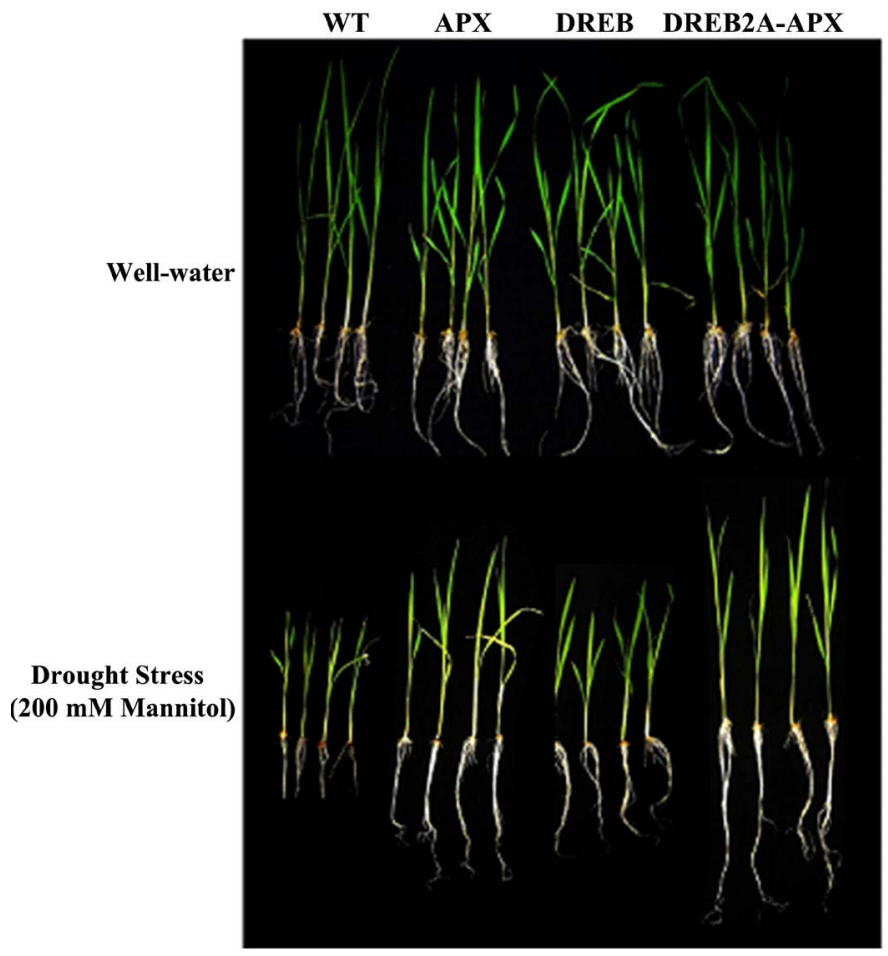

(B)

Figure 5. Seedlings of 7 day old WT and DREB2A, APX and DREB2A-APX transgenic lines after germination on (A) MS medium containing $200 \mathrm{mM}$ mannitol, (B) Vermiculite for one week with $200 \mathrm{mM}$ mannitol supplemented Hoagland's solution.

Table 2. Germination rates of DREB, APX and DREB-APX transgenic rice line seeds under untreated, and drought stress conditions. Values represent mean \pm S.E from three independent experiments Values were significant at $0.05 \%$ level.

\begin{tabular}{ccc}
\hline Lines & $\begin{array}{c}\text { Untreated } \\
(\%)\end{array}$ & $\begin{array}{c}\text { Drought }(200 \mathrm{mM} \text { mannitol) } \\
(\%)\end{array}$ \\
\hline WT & 100 & $23.59 \pm 2.87$ \\
DREB & 100 & $73.15 \pm 6.28$ \\
APX & 100 & $75.97 \pm 4.98$ \\
DREB-APX & 100 & $84.62 \pm 5.12$ \\
\hline
\end{tabular}


Table 3. Survival rate, total biomass, shoot and root lengths of DREB, APX and DREBAPX transgenic rice plantsunder well-water and drought stress. Values represent mean \pm S.E from three independent experiments Values were significant at $0.05 \%$ level.

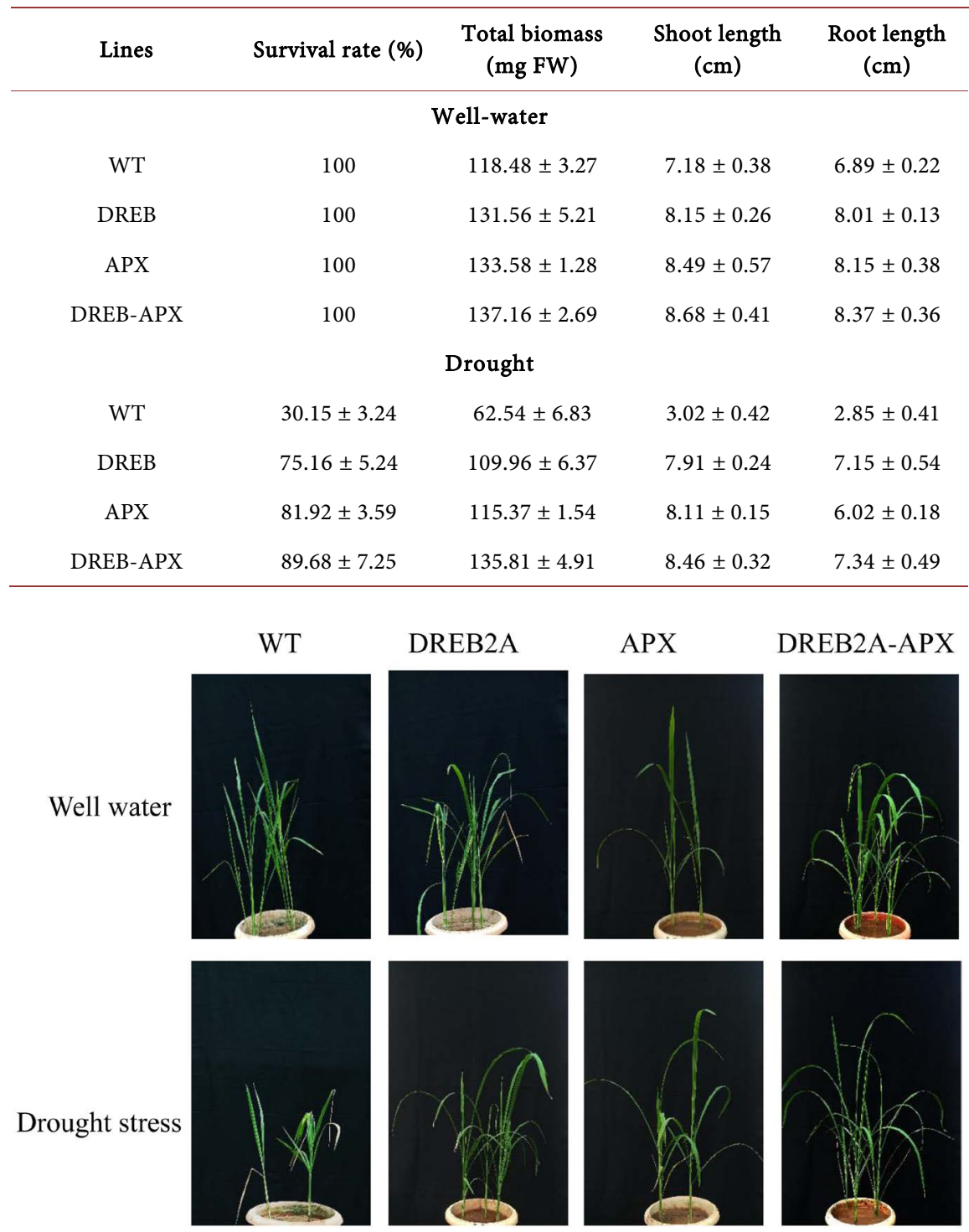

Figure 6. Transgenic DREB2A, APX and DREB2A-APX and WT plants subjected to drought stress by withholding water for 7 days and allowed to grow under normal conditions. WT plants are retarded in growth and transgenic lines continue to grow.

$\left(1.37 \pm 0.018,1.42 \pm 0.061\right.$ and $\left.1.69 \pm 0.024 \mathrm{mg} \cdot \mathrm{g}^{-1} \mathrm{FW}\right)$ chlorophyll content compared to WT control $\left(0.81 \pm 0.036 \mathrm{mg} \cdot \mathrm{g}^{-1} \mathrm{FW}\right)$ plants under drought stress conditions (Figure 7(A)). However, no significant difference was observed between transgenic and WT control plants under normal environmental conditions.

The reducing sugars estimated in transgenic and WT control plants did not show any significant differences under normal conditions (Figure $7(B)$ ). Whereas, in drought stress conditions, DREB2A, APX and DREB2A-APX transgenic lines accumulated higher $\left(1.13 \pm 0.037,1.21 \pm 0.019\right.$ and $\left.1.39 \pm 0.041 \mu \mathrm{g} \cdot \mathrm{g}^{-1} \mathrm{FW}\right)$ 


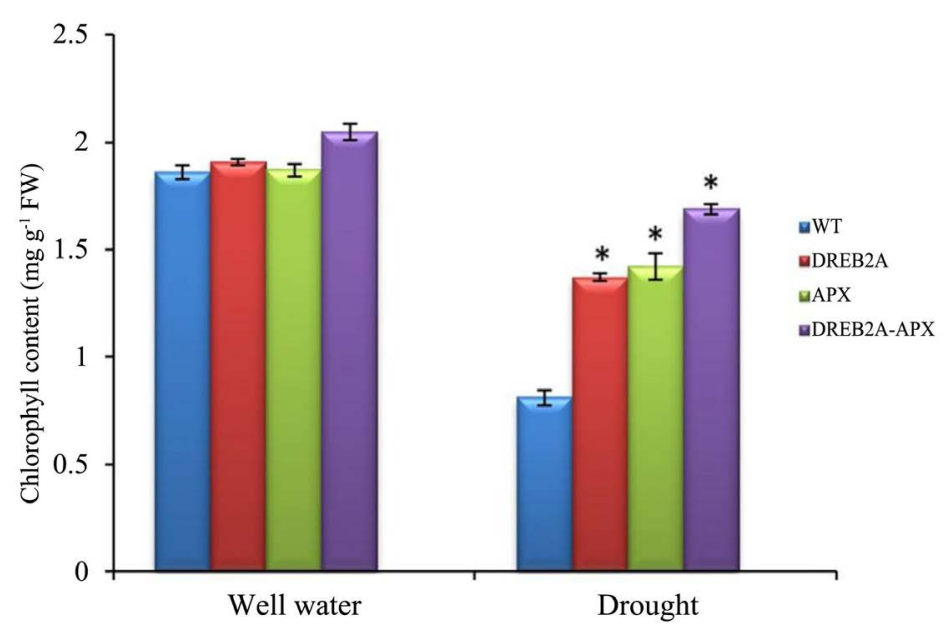

(A)
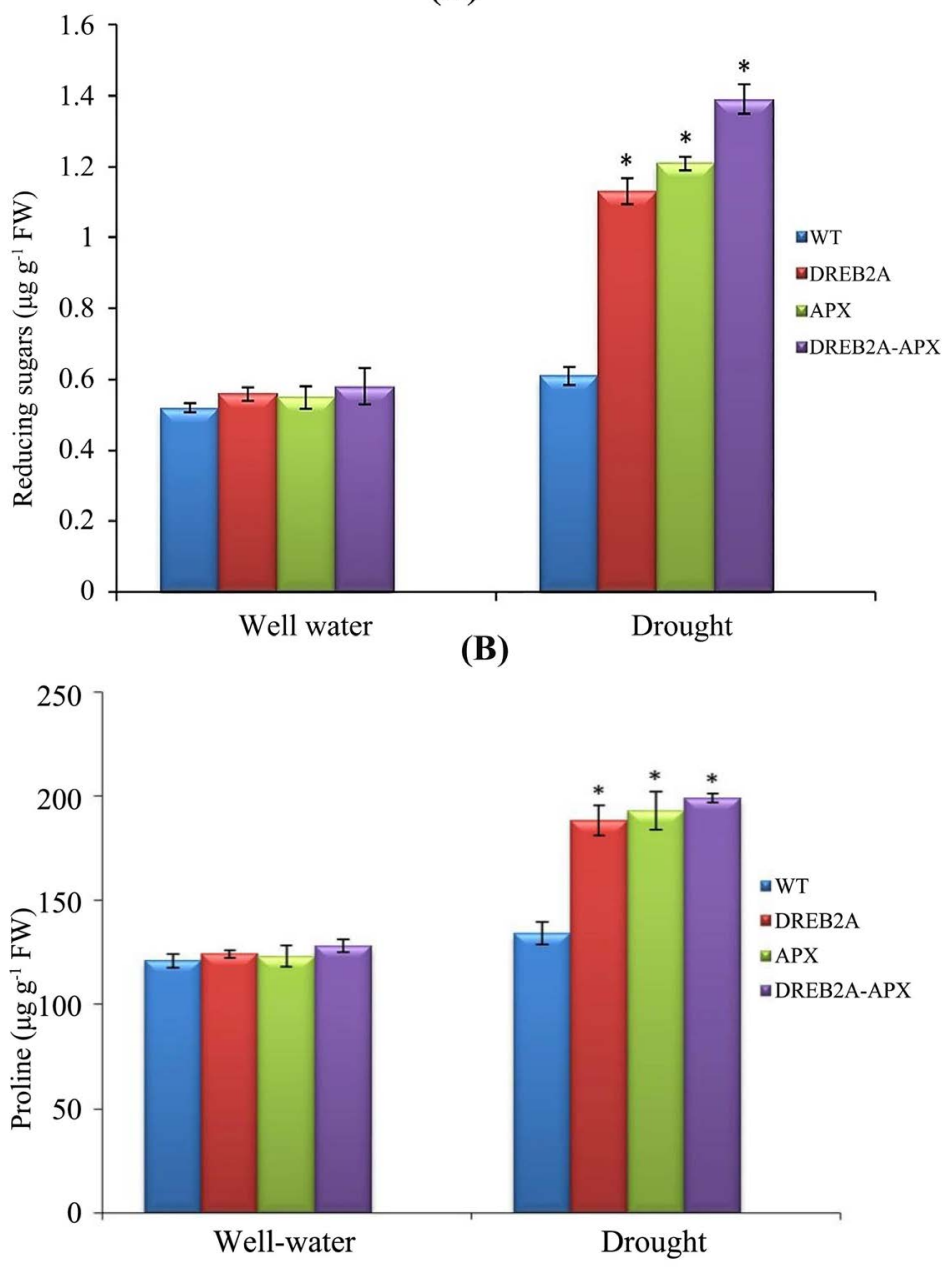

(C)

Figure 7. Physiological parameters chlorophyll, reducing sugars and proline content in leaves of 65 days old vegetative stage rice plants in well watered conditions and treated to drought stress by withholding water for 7 days in WT and transgenic lines DREB2A, APX and DREB2A-APX. (A) Chlorophyll content (mg.g $\left.{ }^{-1} \mathrm{FW}\right),(B)$ Reducing sugars $\left(\mu \mathrm{g} \cdot \mathrm{g}^{-1}\right.$ FW), (C) Proline content $\left(\mu \mathrm{g} \cdot \mathrm{g}^{-1} \mathrm{FW}\right)$. 
amounts of reducing sugars in comparison to WT control $\left(0.61 \pm 0.026 \mu \mathrm{g} \cdot \mathrm{g}^{-1}\right.$ FW) plants.

Higher accumulation of proline contents $(188.54 \pm 7.15,193.18 \pm 9.31$ and $199.11 \pm 2.17 \mu \mathrm{g} \cdot \mathrm{g}^{-1} \mathrm{FW}$ ) were observed in DREB2A, APX and DREB2A-APX transgenic lines than that of WT control (134.27 $\left.\pm 5.28 \mu \mathrm{g} \cdot \mathrm{g}^{-1} \mathrm{FW}\right)$ plants under drought stress conditions (Figure $7(C)$ ). In contrast, no significant differences were exhibited by transgenic and WT control plants under normal conditions.

\subsection{MDA Content}

MDA content of WT control and transgenic plants were measured both under normal and drought stress conditions. Under normal conditions, the MDA content was merely same in transgenic and WT control plants. Under 7 days of drought stress conditions, WT control $\left(27.54 \pm 0.15 \mathrm{nmol} \cdot \mathrm{g}^{-1} \mathrm{FW}\right)$ plants disclosed higher accumulation of MDA content, while the transgenic lines DREB2A, APX and DREB2A-APX showed increased $(15.21 \pm 0.75,13.58 \pm 0.84$ and 12.69 $\left.\pm 0.91 \mathrm{nmol} \cdot \mathrm{g}^{-1} \mathrm{FW}\right) \mathrm{MDA}$ content but less than that of WT control plants (Figure 8).

\subsection{APX, SOD and Catalase Enzyme Activities}

To assess the $\mathrm{H}_{2} \mathrm{O}_{2}$ detoxifying capability in transgenic lines along with WT controls plants APX enzyme acitivity was quantified. The APX activity observed was significantly higher in DREB2A, APX and DREB2A-APX transgenic lines (3.694 $\pm 0.024,3.896 \pm 0.017$ and $4.127 \pm 0.069 \mu \mathrm{mol} \cdot \mathrm{min}^{-1} \cdot \mathrm{g}^{-1} \mathrm{FW}$, respectively) than WT control $\left(1.957 \pm 0.053 \mu \mathrm{mol} \cdot \mathrm{min}^{-1} \cdot \mathrm{g}^{-1} \mathrm{FW}\right)$ plants under drought stress conditions (Figure 9(A)). In contrast, the APX activity under normal conditions was almost same in transgenic and WT control plants (Figure 9(A)).

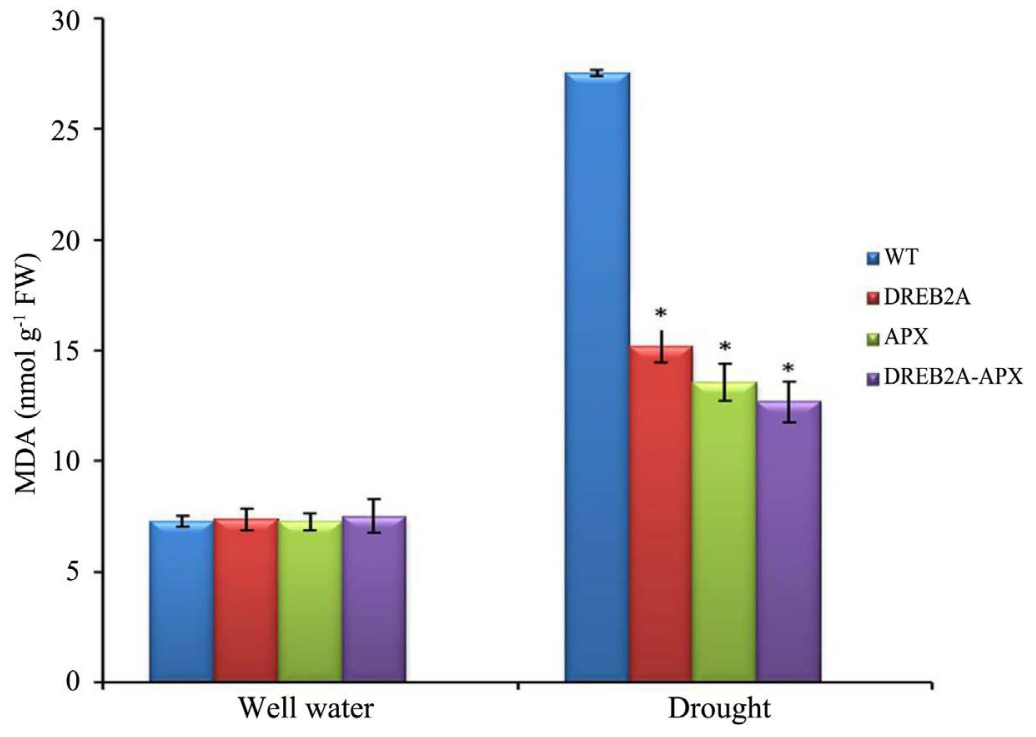

Figure 8. MDA content in leaves of 65 days old vegetative stage rice plants well watered conditions and treated to drought stress by withholding water for 7 days in WT and transgenic DREB2A, APX and DREB2A-APX lines. 


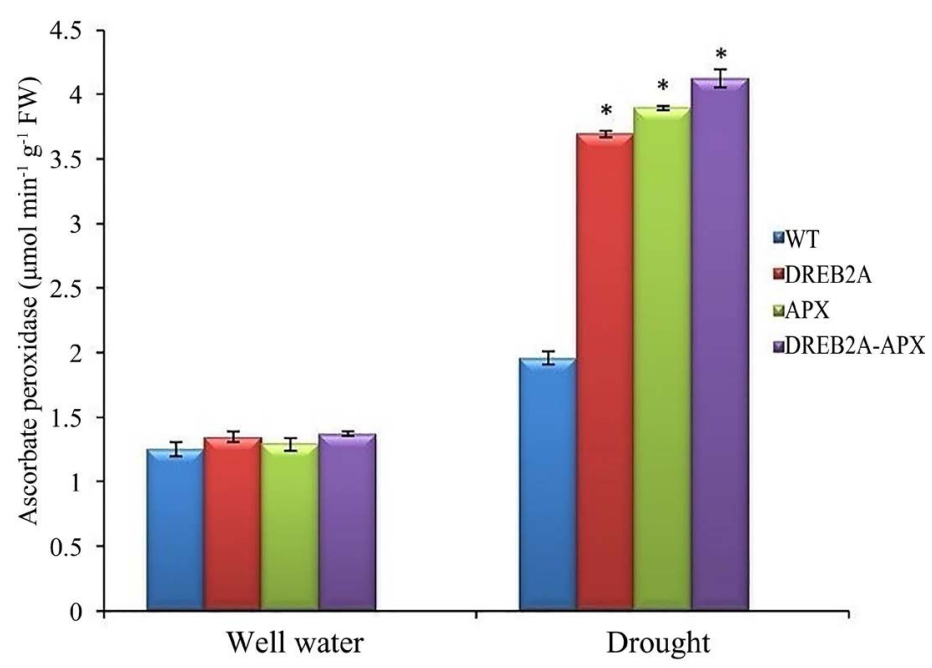

(A)

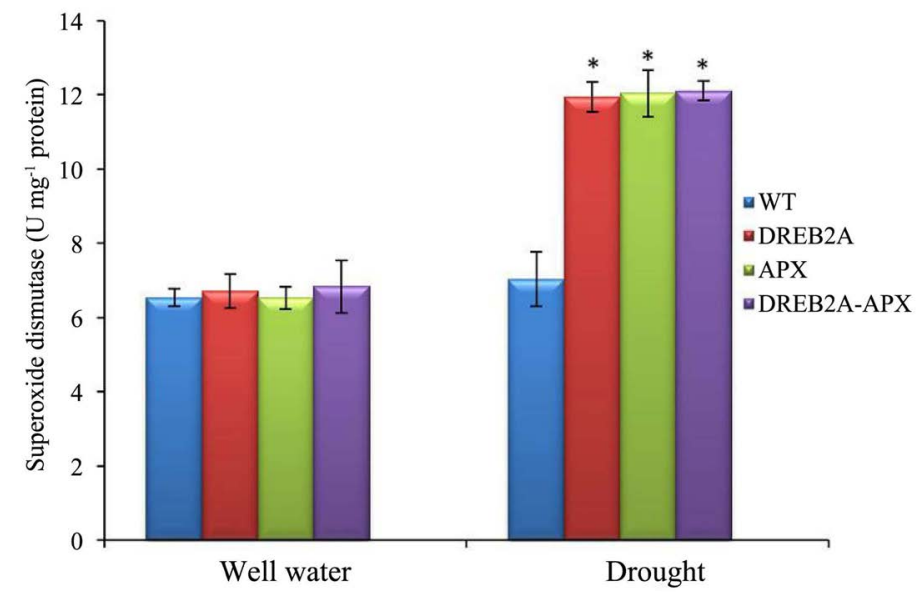

(B)

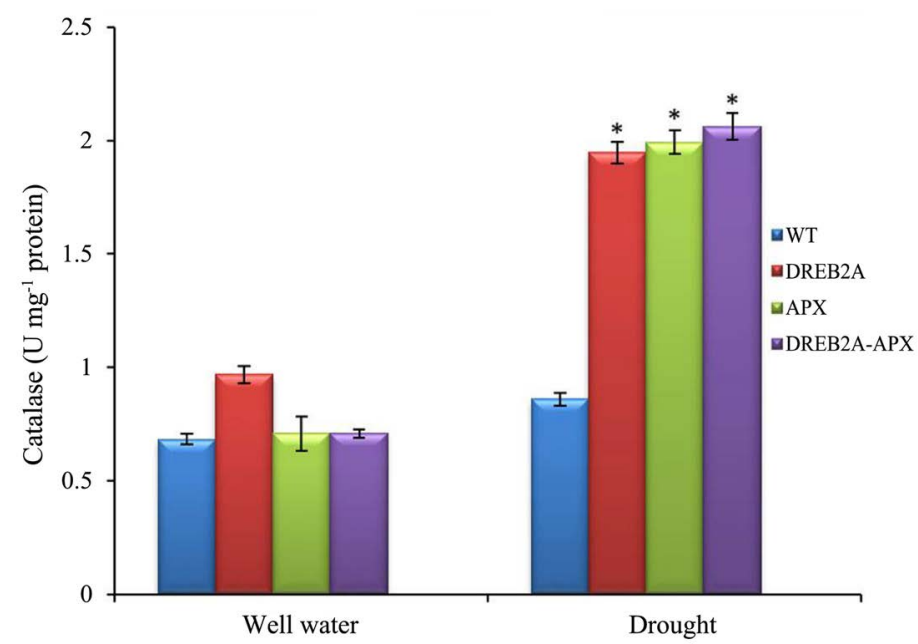

(C)

Figure 9. Antioxidative activities of APX, SOD and catalase enzymes in leaves of 65 days old vegetative stage plants treated to well watered conditions and drought stress for 7 days by withholding water in WT and transgenic DREB2A, APX and DREB2A-APX lines. (A) APX activity measured in $\mu \mathrm{mol} \cdot \mathrm{min}^{-1} \cdot \mathrm{g}^{-1} \mathrm{FW}$, (B) SOD activity in U/mg protein, (C) Catalase activity measured in $\mathrm{U} / \mathrm{min} \mathrm{mg}$ protein. 
To evaluate the free radical detoxification ability, SOD activity was assessed in transgenic and WT control plants under normal and drought stress conditions. After 7 days of drought stress conditions, DREB2A, APX and DREB2A-APX transgenic lines showed higher SOD activity $(11.94 \pm 0.41,12.04 \pm 0.62$ and $12.11 \pm 0.26 \mathrm{U} / \mathrm{mg}$ protein) than WT control $(7.04 \pm 0.73 \mathrm{U} / \mathrm{mg}$ protein) plants (Figure 9(B)). Contrastingly, no significant differences were observed between transgenic lines and WT control plants under normal conditions (Figure 9(B)).

To analyse the $\mathrm{H}_{2} \mathrm{O}_{2}$ detoxification ability, transgenic lines along with WT control plants were assessed for catalase activity. Much higher catalase activity $(1.947 \pm 0.046,1.993 \pm 0.053$ and $2.064 \pm 0.059 \mathrm{U} / \mathrm{mg}$ protein) was observed in DREB2A, APX and DREB2A-APX transgenic lines compared to the activity recorded in WT control $(0.861 \pm 0.028 \mathrm{U} / \mathrm{mg}$ protein) plants (Figure $9(\mathrm{C})$ ). In contrast, no significant differences in catalase activity were observed between transgenic and WT control plants under normal conditions (Figure 9(C)).

\subsection{Photosynthetic Leaf Gas Exchange Physiology}

Randomly selected upper young leaves of transgenic and WT control plants were used for acquiring the data on net photosynthetic rates $\left(\mu \mathrm{mol} \cdot \mathrm{m}^{-2} \cdot \mathrm{s}^{-1}\right)$ under normal and drought stress conditions. The photosynthetic rates recorded in DREB2A, APX and DREB2A-APX transgenic lines were much higher (10.57 \pm $0.1,10.68 \pm 0.5$ and $\left.11.89 \pm 0.4 \mu \mathrm{mol} \cdot \mathrm{m}^{-2} \cdot \mathrm{s}^{-1}\right)$ compared to WT control $(7.54 \pm$ $0.3 \mu \mathrm{mol} \cdot \mathrm{m}^{-2} \cdot \mathrm{s}^{-1}$ ) plants under drought stress conditions (Figure 10). Conversely, under normal conditions no significant differences in photosynthetic rates were found between transgenic and WT control plants.

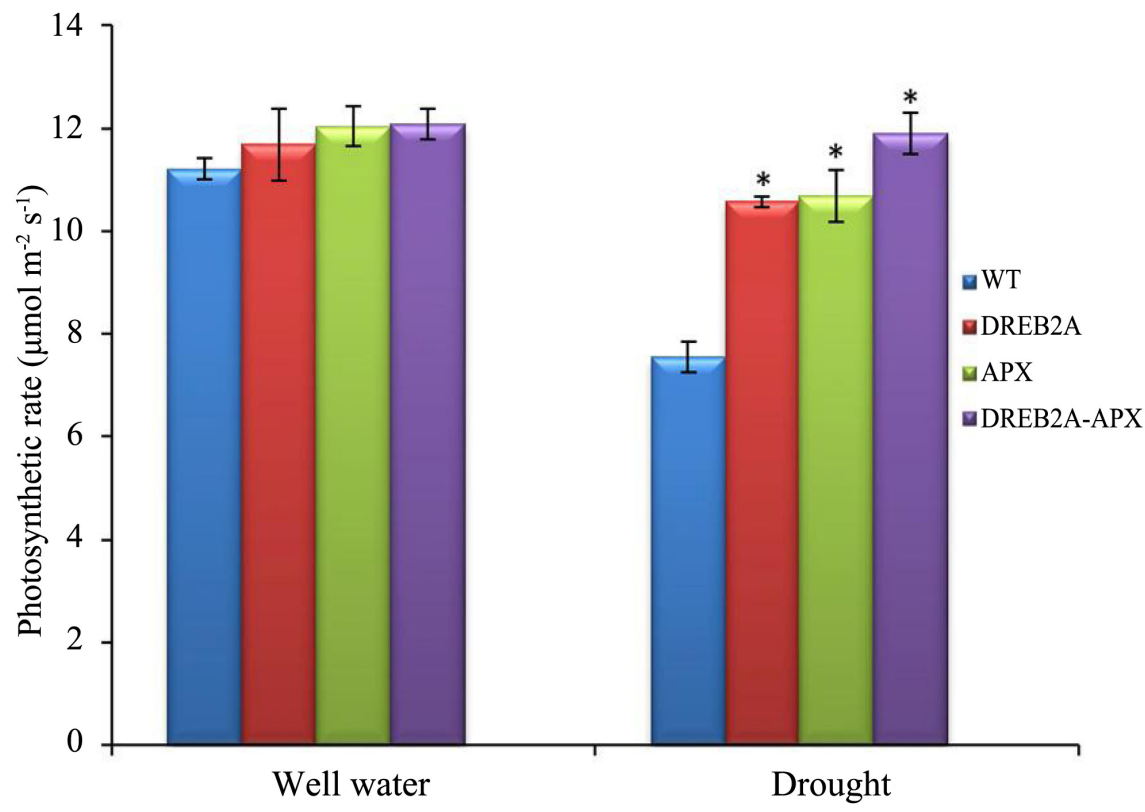

Figure 10. Photosynthetic rates in leaves of 65 days old vegetative stage rice plants grown in well watered conditions and treated to drought stress for 7 days by withholding water in WT and transgenic DREB2A, APX and DREB2A-APX lines. 


\subsection{Water Use Efficiency and Relative Water Content}

Randomly selected upper young leaves of transgenic and WT control plants were used for acquiring the data on water-use-efficiency ( WUEi $=A / E ; \mathrm{mmol} \mathrm{CO}_{2}$ $\mathrm{mol}^{-1} \mathrm{H}_{2} \mathrm{O}$ ) under normal and drought stress conditions. The WUE of transgenic lines and WT control plants did not show any significant differences under normal conditions (Figure 11(A)). Higher WUE of $2.07 \pm 0.08,2.10 \pm 0.07$ and $2.13 \pm 0.03 \mathrm{mmol} \mathrm{CO}_{2} \mathrm{~mol}^{-1} \mathrm{H}_{2} \mathrm{O}$, respectively, were recorded by DREB2A, APX and DREB2A-APX transgenic lines than that of WT control $(1.09 \pm 0.01 \mathrm{mmol}$ $\mathrm{CO}_{2} \mathrm{~mol}^{-1} \mathrm{H}_{2} \mathrm{O}$ ) plants under stress conditions (Figure 11(A)).

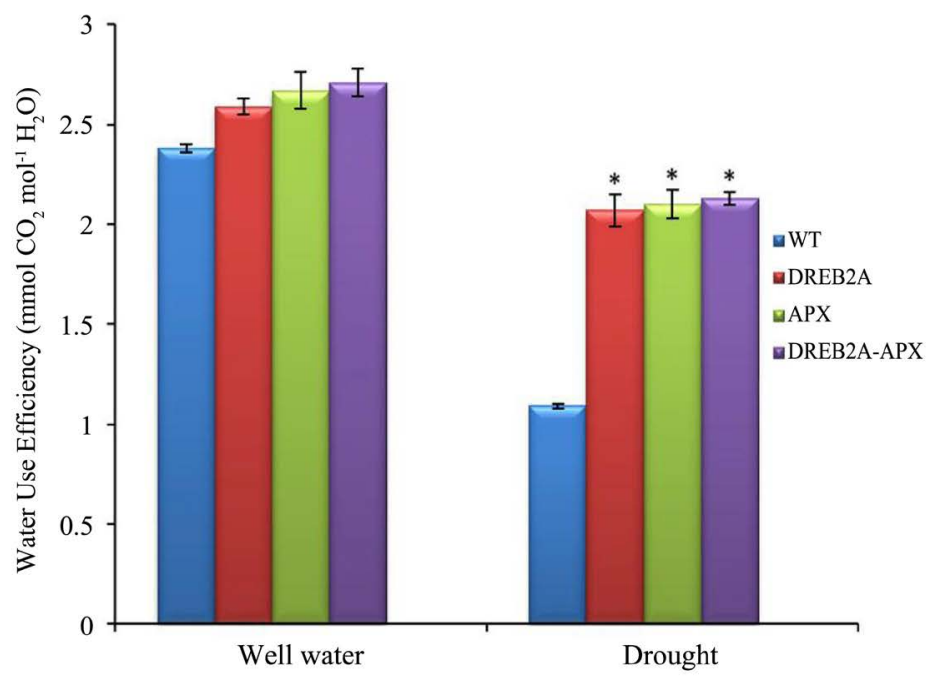

(A)

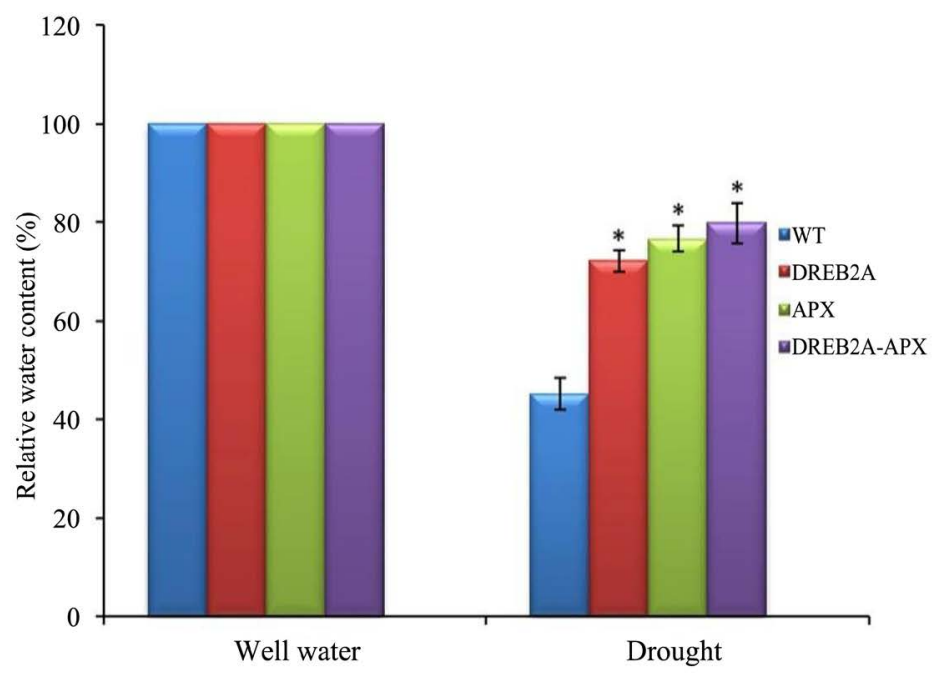

(B)

Figure 11. Water use efficiency and relative water content in leaves of 65 days old vegetative stage rice plants grown in normal well watered conditions and treated to drought stress for 7 days by withholding water in WT and transgenic DREB2A, APX and DREB2A-APX lines. (A) Water use efficiency (WUE (mmol $\left.\mathrm{CO}_{2} \mathrm{~mol}^{-1} \mathrm{H}_{2} \mathrm{O}\right)$ ) and (B) Relative water content. 
To analyse the water status of the plants, the relative water content of transgenic and WT control plants were measured after 7 days of drought stress treatment. The transgenic lines DREB2A, APX and DREB2A-APX disclosed higher RWC $(72.21 \% \pm 2.18 \%, 76.69 \% \pm 2.59 \%$ and $79.86 \% \pm 4.05 \%)$ compared to WT control $(45.18 \% \pm 3.17 \%)$ plants under drought stress conditions (Figure 11(B)).

\subsection{Panicle Size and Grain Yield}

At reproductive stage drought stress tolerance was assessed by withholding water for 7 days in transgenic lines along with WT control plants (85 - 95 days old). After drought treatment, the plants were allowed to grow under normal conditions till maturity and the data on panicle length and grain yield/plant were recorded. At maturity, transgenic lines DREB2A, APX and DREB2A-APX developed longer panicles $(14.25 \pm 0.58,15.09 \pm 0.28$ and $15.98 \pm 0.52 \mathrm{~cm})$ compared to WT control plants $(7.21 \pm 1.21 \mathrm{~cm})$ under drought stress conditions (Table 4). In addition, DREB2A, APX and DREB2A-APX transgenic lines produced increased $(409.47 \pm 3.29,429.31 \pm 4.19$ and $453.17 \pm 5.93$ grains $)$ grains/plant than that of WT control (238.69 \pm 6.31 grains) plants under drought stress conditions (Figure 12 and Table 4).

\subsection{1. qRT-PCR Analysis of DREB2A and APX}

The change in the expression levels of the DREB2A in DREB2A transgenic and APX in APX and DREB2A-APX transgenic lines were found to be higher compared to WT control plants under well water and drought stress conditions (Figure 13).

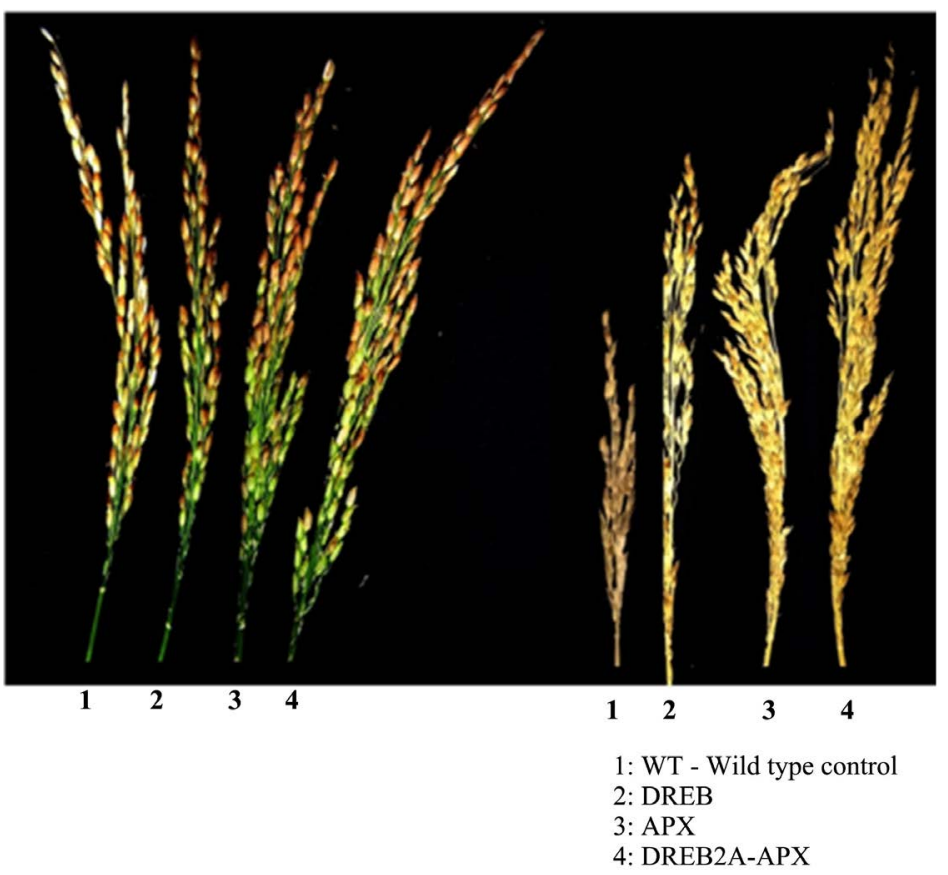

Figure 12. DREB2A, APX, DREB2A-APX and WT plants subjected to well-water and drought stress showing panicle length and grains per plant. 
Table 4. Panicle length and grains/plant in 85 - 95 day old rice plants treated to drought stress before maturity for 7 days and recovered with normal conditions in WT and transgenic DREB2A, APX and DREB2A-APX lines.

\begin{tabular}{ccc}
\hline Lines & Well water & Drought \\
\hline WT & & Panicle length \\
DREB2A & $16.15 \pm 1.48$ & $7.21 \pm 1.21$ \\
APX & $16.57 \pm 0.57$ & $14.25 \pm 0.58$ \\
DREB2A-APX & $17.35 \pm 0.98$ & $15.09 \pm 0.28$ \\
& $16.98 \pm 0.47$ & $15.98 \pm 0.52$ \\
WT & & Grains/plant \\
DREB2A & $449.21 \pm 2.69$ & $238.69 \pm 6.31$ \\
APX & $462.12 \pm 4.09$ & $409.47 \pm 3.29$ \\
DREB2A-APX & $498.95 \pm 6.32$ & $429.31 \pm 4.19$ \\
\hline
\end{tabular}

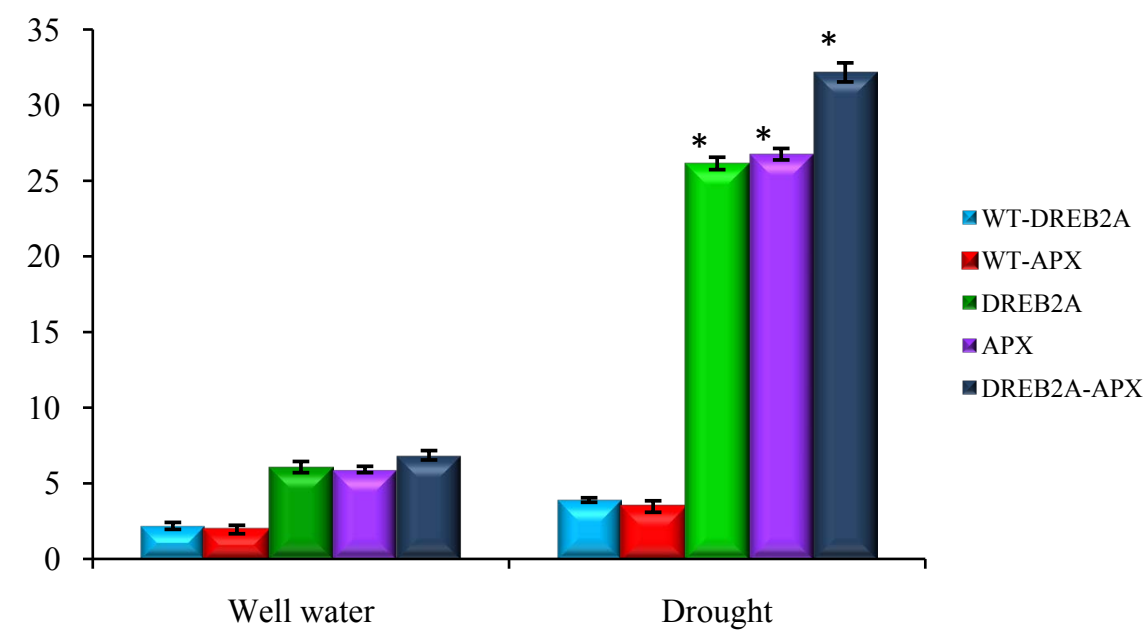

Figure 13. qRT-PCR analysis of DREB2A and APX gene expression in WT control and DREB2A, APX and DREB2A-APX transgenic lines.

\section{Discussion}

Rice comprises of $27 \%$ in total cereal utilization and the production has to be increased rapidly to feed the ever growing population in the future years. The crop productivity is adversely affected by frequent global climate changes, in addition, various abiotic stresses interfere with different stages of rice crop development and yield [36]. Among different stresses, drought is the most common and critical environmental factor that limits the rice crop productivity. Transgenic approach technology generated many drought tolerant rice varieties, but a very few exhibited improved grain yield under field conditions [37]. Drought tolerance is a complex mechanism controlled by many genes in rice genome. Development of drought tolerant transgenic plants by introduction of drought resistant gene(s) is considered to be the potential effort for improving the rice crop yield. 
Assessing the drought tolerance at germination stage revealed higher germination rates in the transgenic lines compared to WT control plants, suggesting that APX gene play a vital role in imparting drought tolerance in these lines. $\mathrm{Ca}$ janus cajan hybrid-proline-rich protein encoding gene (CcHyPRP) when overexpressed in rice under the control of CaMV $35 \mathrm{~S}$ promoter exhibited higher seed germination rates under drought stress conditions [38]. Transgenic seeds of Arabidopsis, overexpressing OsSIZ1, when germinated on MS medium supplemented with PEG $(0.5 \mathrm{M})$ showed higher germination rates in comparison to control plant seeds [39].

The transgenic DREB2A, APX and DREB2A-APX lines showed increased chlorophyll content than WT control plants under drought stress conditions, indicating that the transgenic plants ability to harvest the light energy and stabilize the membranes to increase the photosynthetic potential under stress conditions. Likewise, overexpression of $O$. sativa SUMO E3 ligase (OsSIZ1) in Arabidopsis lead to accumulation of higher chlorophyll contents and also exhibited improved tolerance to drought and salt stresses [39]. In addition, overexpression of CCHyPRP in transgenic rice showed higher chlorophyll content under different abiotic stress conditions [38].

The DREB2A, APX and DREB2A-APX transgenic lines when subjected to drought stress condition for 7 days, showed increased proline and reducing sugars than WT control plants, indicating that the transgenic plants are more capable in osmotic adjustment and maintaining the integrity of cell membranes under drought conditions. Overexpression of $O$. sativa ornithine $\delta$-aminotransferase (OSOAT) controlled by maize ubiquitin promoter in rice, disclosed higher proline content, leading to enhance tolerance to drought stress [40].

Reduced levels of MDA were identified in DREB2A, APX and DREB2A-APX transgenic lines than WT control plants under drought stress conditions, indicating the involvement of transgene in controlling the lipid peroxidation and contributing to the enhanced tolerance in transgenic plants. Transgenic Arabidopsis expressing Simmondsia chinensis plasma membrane intrinsic protein 1 (ScPIP1) showed reduced MDA content and increased the accumulation of osmotic substances under drought stress conditions [41]. Moreover, co-overexpression of OsGS1; 1/OsGS2 in transgenic rice exhibited higher accumulation of proline and low levels of malondialdehyde (MDA) in transgenic plants suggesting its role in tolerance against different abiotic stresses [42].

Under drought stress condition, higher APX, SOD and catalase activities were exhibited by transgenic DREB2A, APX and DREB2A-APX lines than WT control plants, suggesting the capability of transgenic lines in cell membrane stability, lowering the electrolyte leakage and detoxifying ROS generated under stress conditions. Conversely, overexpression of ZmNF-YB16 in maize, exhibited higher photosynthesis, low electrolyte leakage, membrane stability and higher activity of antioxidants under drought stress conditions [43].

Higher photosynthetic rates and water-use-efficiency were recorded in DREB2A, APX and DREB2A-APX transgenic lines than WT control plants under drought 
stress conditions, suggesting that the transgenic lines potentiality in gas-exchange under drought stress. Likewise, overexpression of small GTP-binding protein (OsRab7) in transgenic rice, showed higher gas-exchange resulting in increased photosynthetic rates under drought and salinity stresses [44]. Similarly, the antisense RNA silencing lines of AUXIN RESPONSE FACTOR 4 (ARF4) disclosed higher chlorophyll content and higher water use efficiency under stress conditions [45].

The DREB2A, APX and DREB2A-APX transgenic lines exhibited higher relative water content compared to WT control plants under drought stress conditions, suggesting the capability of transgenic lines in maintaining the water status by balancing the water supply to leaf and water evaporation through transpiration. Similarly, overexpression of R2R3-MYB genes (ScMYBAS1-2 and ScMYBAS1-3) in transgenic rice disclosed higher relative water content under stress conditions [46].

The transgenic DREB2A, APX and DREB2A-APX lines along with WT control plants when subjected to drought stress for 7 days at reproductive stages exhibited increased panicle size and higher grain/plant compared to WT control plants, suggesting the involvement of APX in modulating the stress responsive genes and increasing the panicle grains/plant under stress conditions. Similarly, overexpression of histone binding protein/transcription factor-1b (OsHBP1b), in transgenic rice disclosed longer panicles, indicating its role in regulating the stress responsive genes for enhanced photosynthesis [47]. Moreover, transgenic rice overexpressing OsNAR2.1 showed higher grain yield under drought stress conditions, evidencing the vital role of OsNAR2.1 in imparting drought tolerance [48].

\section{Conclusion}

For the development of drought tolerant varieties, it is a prerequisite to understand and manipulate various biochemical pathways and molecular mechanisms that determine the plant growth and yield of rice crop under drought stress conditions. In the present investigation, APX gene is co-expressed with DREB2A under the control of constitutive promoter CaMV $35 \mathrm{~S}$ in rice and validated the function of APX gene under the drought stress conditions. The results suggest that co-expression of APX and DREB2A can be potential candidate genes for combined action of genes and physiological activation of anti-oxidative defense system to scavenge ROS produced in drought stress and for the development of drought tolerant rice variety.

\section{Acknowledgements}

A.S acknowledges the support of funding from DST-PURSE-II, UGC-UPE-FAR and RUSA schemes for the research work.

\section{Conflicts of Interest}

The authors declare no conflicts of interest regarding the publication of this paper. 


\section{References}

[1] Vinay, K., Datir, S., Khare, T. and Shriram, V. (2019) Advances in Biotechnological Tools: Improving Abiotic Stress Tolerance in Rice. In: Hasanuzzaman, M., Fujita, M., Nahar, K. and Biswas, J., Eds., Advances in Rice Research for Abiotic Stress Tolerance, Woodhead Publishing, Sawston, 615-632. https://doi.org/10.1016/B978-0-12-814332-2.00030-7

[2] Basu, S., Ramegowda, V., Kumar, A. and Pereira, A. (2016) Plant Adaptation to Drought Stress. F1000Research, 5, 1554. https://doi.org/10.12688/f1000research.7678.1

[3] Rasheed, A., et al. (2020) A Critical Review on the Improvement of Drought Stress Tolerance in Rice (Oryza sativa L.). Notulae Botanicae Horti Agrobotanici Cluj-Napoca, 48, 1756-1788. https://doi.org/10.15835/nbha48412128

[4] Pantuwan, G., Fukai, S., Cooper, M., Rajatasereekul, S. and O’Toole, J.C. (2002) Yield Response of Rice (Oryza sativa L.) Genotypes to Drought under Rainfed Lowland: 3. Plant Factors Contributing to Drought Resistance. Field Crops Research, 73, 181-200. https://doi.org/10.1016/S0378-4290(01)00194-0

[5] Batlang, U., Baisakh, N., Ambavaram, M.M.R. and Pereira, A. (2013) Phenotypic and Physiological Evaluation for Drought and Salinity Stress Responses in Rice. In: Rice Protocols, Humana Press, Totowa, 209-225. https://doi.org/10.1007/978-1-62703-194-3 15

[6] Babita, M., Maheswari, M., Rao, L.M., Shanker, A.K. and Gangadhar Rao, D. (2010) Osmotic Adjustment, Drought Tolerance and Yield in Castor (Ricinus communis L.) Hybrids. Environmental and Experimental Botany, 69, 243-249. https://doi.org/10.1016/j.envexpbot.2010.05.006

[7] Sumita, K., Roy, S., Singh, P., Singla-Pareek, S. and Pareek, A. (2013) Cyclophilins: Proteins in Search of Function. Plant Signalling \& Behaviour, 8, e22734. https://doi.org/10.4161/psb.22734

[8] Pour, M.P., Moieni, A. and Komatsu, S. (2012) Comparative Proteome Analysis of Drought-Sensitive and Drought-Tolerant Rapeseed Roots and Their Hybrid $\mathrm{F}_{1}$ Line under Drought Stress. Amino Acids, 43, 2137-2152. https://doi.org/10.1007/s00726-012-1299-6

[9] Ramanjulu, S. and Bartels, D. (2002) Drought- and Desiccation-Induced Modulation of Gene Expression in Plants. Plant, Cell \& Environment, 25, 141-151. https://doi.org/10.1046/j.0016-8025.2001.00764.x

[10] Hiroshi, A., Yamaguchi-Shinozakai, K., Urao, T., Iwasakai, T.S., Hosokawa, D. and Shinozaki, K. (1997) Role of Arabidopsis MYC and MYB Homologs in Droughtand Abscisic Acid-Regulated Gene Expression. Plant Cell, 9, 1859-1868. https://doi.org/10.1105/tpc.9.10.1859

[11] Yoh, S., Maruyama, K., Osakabe, Y., Qin, F., Seki, M., Shinozakai, K., Ko, K. and Yamaguchi-Shinozakai, K. (2006) Functional Analysis of an Arabidopsis Transcription Factor DREB2A, Involved in Drought Responsive Gene Expression. Plant Cell, 18, 1292-1309. https://doi.org/10.1105/tpc.105.035881

[12] Yamaguchi-Shinozaki, K. and Shinozaki, K. (1994) A Novel cis-Acting Element in an Arabidopsis Gene Is Involved in Responsiveness to Drought, Low-Temperature, or High-Salt Stress. Plant Cell, 6, 251-264. https://doi.org/10.1105/tpc.6.2.251

[13] Singh, G.S. and Tuteja, N. (2010) Reactive Oxygen Species and Antioxidant Machinery in Abiotic Stress Tolerance in Crop Plants. Plant Physiology and Biochemistry, 48, 909-930. https://doi.org/10.1016/j.plaphy.2010.08.016 
[14] Veselin Dimitrov, P. and Van Breusegem, F. (2012) Hydrogen Peroxide-A Central Hub for Information Flow in Plant Cells. AoB Plants, 2012, pls014. https://doi.org/10.1093/aobpla/pls014

[15] Asada, K. (1992) Ascorbate Peroxidase: A Hydrogen Peroxide-Scavenging Enzyme in Plants. Physiologia Plantarum, 85, 235-241. https://doi.org/10.1111/j.1399-3054.1992.tb04728.x

[16] Mittler, R. and Zilinskas, B.A. (1994) Regulation of Pea Cytosolic Ascorbate Peroxidase and Other Antioxidant Enzymes during the Progression of Drought Stress and Following Recovery from Drought. The Plant Journal, 5, 397-405. https://doi.org/10.1111/j.1365-313X.1994.00397.x

[17] Wilson, P.B., Estavillo, G.M., Field, K.J., Pornsiriwong, W., Carroll, A.J., Howell, K.A., Woo, N.S., Lake, J.A., Smith, S.M., Millar, H.A., et al. (2009) The Nucleotide/Phosphatase SAL1 Is a Negative Regulator of Drought Tolerance in Arabidopsis. The Plant Journal, 58, 299-317. https://doi.org/10.1111/j.1365-313X.2008.03780.x

[18] Esavillo, G.M., Crisp, P.A., Pornsiriwong, W., Wirtz, M., Collinge, D., Carrie, C., Giraud, E., Whelan, J., David, P., Javot, H., et al. (2011) Evidence for a SAL1-PAP Chloroplast Retrograde Pathway That Functions in Drought and High Light Signaling in Arabidopsis. Plant Cell, 23, 3992-4012.

https://doi.org/10.1105/tpc.111.091033

[19] Roxas, V.P., Smith, R.K., Allen, E.R. and Allen, R.D. (1997) Overexpression of Glutathione S-Transferase/Glutathione Peroxiase Enhances the Growth of Transgenic Tobacco Seedlings during Stress. Nature Biotechnology, 15, 988-991. https://doi.org/10.1038/nbt1097-988

[20] Dowler, C., Slooten, L., Vandenbranden, S., Rycke, R.D., Botterman, J., Sybesma, C. and van Montagu, M. (1991) Manganese Superoxide Dismutase Can Reduce Cellular Damage Mediated by Oxygen Radicals in Transgenic Plants. EMBO Journal, 10, 1723-1732. https://doi.org/10.1002/j.1460-2075.1991.tb07696.x

[21] Li, Y.J., Hai, R., Inze, D.L., Du, X.H., Jiang, X.N. and Lu, H. (2009) Overexpression of a Populus Peroxisomal Ascorbate Peroxidase (Pp APX) Gene in Tobacco Plants Enhances Stress Tolerance. Plant Breeding, 128, 404-410. https://doi.org/10.1111/j.1439-0523.2008.01593.x

[22] Cao, S., Du, X.H., Li, L.H., Liu, Y.D., Zhang, L., Pan, X., Li, Y., Li, H. and Lu, H. (2017) Overexpression of Populus tomentosa Cytosolic Ascorbate Peroxidase Enhances Abiotic Stress Tolerance in Tobacco Plants. Russian Journal of Plant Physiology, 64, 224-234. https://doi.org/10.1134/S1021443717020029

[23] Agarwal, P.K., Gupta, K., Lopato, S. and Agarwal, P. (2017) Dehydration Responsive Element Binding Transcription Factors and Their Applications for the Engineering of Stress Tolerance. Journal of Experimental Botany, 68, 2135-2148. https://doi.org/10.1093/jxb/erx118

[24] Kasuga, M., Liu, Q., Miura, S., Yamaguchi-Shinozaki, K. and Shinozaki, K. (1999) Improving Plant Drought, Salt and Freezing Tolerance by Gene Transfer of a Single Stress Inducible Transcription Factor. Nature Biotechnology, 17, 287-291. https://doi.org/10.1038/7036

[25] Ramesh, S., Nagadhara, D., Reddy, V.D. and Rao, K.V. (2004) Production of Transgenic Indica Rice Resistant to Yellow Stem Borer and Sap-Sucking Insects, Using Super-Binary Vectors of Agrobacterium tumefaciens. Plant Science, 166, 1077-1085. https://doi.org/10.1016/j.plantsci.2003.12.028

[26] Sambrook, J. and Russell, D.W. (2001) Molecular Cloning: A Laboratory Manual. 
Cold Spring Harbor Laboratory Press, New York.

[27] Lichtenthaler, H.K. and Wellburn, A.R. (1983) Determinations of Total Carotenoids and Chlorophylls a and b of Leaf Extracts in Different Solvents. Biochemical Society Transactions, 603, 591-592. https://doi.org/10.1042/bst0110591

[28] Miller, G.L. (1959) Use of Dinitrosalicylic Acid Reagent for Determination of Reducing Sugar. Analytical Chemistry, 3, 426-428. https://doi.org/10.1021/ac60147a030

[29] Abraham, E., Hourton-Cabassa, C., Erdei, L. and Szabados, L. (2010) Methods for Determination of Proline in Plants. Methods in Molecular Biology, 639, 317-331. https://doi.org/10.1007/978-1-60761-702-0 20

[30] Feutrys, H.D., Krsnik-Rasol, M., Poder, D. and Menez, J.F. (1995) Estimation of Free and Bound MDA in Plant Extracts. Comparison between Spectrophotometric and HPLC Methods. In: Chen, T. and Zhang, B., Eds., Plant Lipid Metabolism, Springer, Dordrecht, 259-261. https://doi.org/10.1007/978-94-015-8394-7 71

[31] Nakano, Y. and Kozi, A. (1987) Purification of Ascorbate Peroxidase in Spinach Chloroplasts; Its Inactivation in Ascorbate-Depleted Medium and Reactivation by Monodehydroascorbate Radical. Plant and Cell Physiology, 28, 131-140.

[32] Murshed, R., Lopez-Lauri, F. and Sallanon, H. (2008) Microplate Quantification of Enzymes of the Plant Ascorbate-Glutathione Cycle. Analytical Biochemistry, 383, 320-322. https://doi.org/10.1016/j.ab.2008.07.020

[33] Giannopolitis, C.N. and Ries, S.K. (1977) Superoxide Dismutases. I. Occurrence in Higher Plants. Plant Physiology, 59, 309-314. https://doi.org/10.1104/pp.59.2.309

[34] Aebi, H. (1984) Catalase in Vitro. Methods in Enzymology, 105, 121-126. https://doi.org/10.1016/S0076-6879(84)05016-3

[35] Gonzalez, L. and Gonzalez-Vilar, M. (2001) Determination of Relative Water Content. In: Reigosa Roger, M.J., Ed., Handbook of Plant Ecophysiology Techniques, Springer, Dordrecht, 207-212.

[36] Calanca, P.P. (2017) Effects of Abiotic Stress in Crop Production. In: Ahmed, M. and Stockle, C.O., Eds., Quantification of Climate Variability, Adaptation and Mitigation for Agricultural Sustainability, Springer, Cham, 165-180.

https://doi.org/10.1007/978-3-319-32059-5 8

[37] Selvaraj, M.G., Ishizaki, T., Valencia, M., Ogawa, S., Dedicova, B., Ogata, T., Yoshiwara, K., et al. (2017) Overexpression of an Arabidopsis thaliana Galactinol Synthase Gene Improves Drought Tolerance in Transgenic Rice and Increased Grain Yield in the Field. Plant Biotechnology Journal, 15, 1465-1477. https://doi.org/10.1111/pbi.12731

[38] Mellacheruvu, S., Srinath, T., Dashavantha, R.V. and Venkateswara, R.K. (2016) Pigeon Pea Hybrid-Proline-Rich Protein $(C c H y P R P)$ Confers Biotic and Abiotic Stress Tolerance in Transgenic Rice. Frontiers in Plant Science, 6, 1167. https://doi.org/10.3389/fpls.2015.01167

[39] Mishra, N., Srivastava, A.P., Esmaeili, N., Hu, W.J. and Shen, G.X. (2018) Overexpression of the Rice Gene OsSIZ1 in Arabidopsis Improves Drought-, Heat-, and Salt-Tolerance Simultaneously. PLOS ONE, 13, e0201716. https://doi.org/10.1371/journal.pone.0201716

[40] You, J., Hu, H.H. and Xiong, L.Z. (2012) An Ornithine $\delta$-Aminotransferase Gene OsOAT Confers Drought and Oxidative Stress Tolerance in Rice. Plant Science, 197, 59-69. https://doi.org/10.1016/j.plantsci.2012.09.002

[41] Wang, X., Gao, F., Bing, J., Sun, W.M., Feng, X.X., Ma, X.F., Zhou, Y.J. and Zhang, 
G.F. (2019) Overexpression of the Jojoba aquaporin Gene, ScPIP1, Enhances Drought and Salt Tolerance in Transgenic Arabidopsis. International Journal of Molecular Sciences, 20, 153. https://doi.org/10.3390/ijms20010153

[42] James, D., Borphukan, B., Fartyal, D., Ram, B., Singh, J., Manna, M., Sheri, V., et al. (2018) Concurrent Overexpression of OsGS1; 1 and OsGS2 Genes in Transgenic Rice (Oryza sativa L.): Impact on Tolerance to Abiotic Stresses. Frontiers in Plant Science, 9, 786. https://doi.org/10.3389/fpls.2018.00786

[43] Wang, B.M., Li, Z.X., Ran, Q.J., Li, P., Peng, Z.H. and Zhang, J.R. (2018) $Z m N F-Y B 16$ Overexpression Improves Drought Resistance and Yield by Enhancing Photosynthesis and the Antioxidant Capacity of Maize Plants. Frontiers in Plant Science, 9, 709. https://doi.org/10.3389/fpls.2018.00709

[44] El-Esawi, M.A. and Alayafi, A.A. (2019) Overexpression of Rice Rab7 Gene Improves Drought and Heat Tolerance and Increases Grain Yield in Rice (Oryza sativa L.). Genes, 10, 56. https://doi.org/10.3390/genes10010056

[45] Bouzroud, S., Barbosa, M.A., Gasparini, K., Fahr, M., Bendaou, N., Bouzayen, M., Zsogon, A., Smouni, A. and Zouine, M. (2019) Loss of Auxin Response Factor 4 Function Alters Plant Growth, Stomatal Functions and Improves Tomato Tolerance to Salinity and Water Deficit. https://doi.org/10.1101/756387

[46] Peixoto-Junior, R.F., de Andrade, L.M., dos Santos Brito, M., Nobile, P.M., et al. (2018) Overexpression of ScMYBAS1 Alternative Splicing Transcripts Differentially Impacts Biomass Accumulation and Drought Tolerance in Rice Transgenic Plants. PLoS ONE, 13, e0207534. https://doi.org/10.1371/journal.pone.0207534

[47] Das, P., Lakra, N., Nutan, K.K., Singla-Pareek, S.L. and Pareek, A. (2019) A Unique bZIP Transcription Factor Imparting Multiple Stress Tolerance in Rice. Rice, 12, 58. https://doi.org/10.1186/s12284-019-0316-8

[48] Chen, J.G., Qi, T.T., Hu, Z., Fan, X.R., Zhu, L.L., Yin, X.M., Xu, G.H. and Fan, X.R. (2019) OsNAR2.1 Positively Regulates Drought Tolerance and Grain Yield under Drought Stress Conditions in Rice. Frontiers in Plant Science, 10, 197. https://doi.org/10.3389/fpls.2019.00197 